\title{
Equality and diversity rhetoric: one size fits all? Globalization and the Portuguese context
}

\author{
Iris Barbosa and Carlos Cabral-Cardoso \\ NEGE-Management Research Unit, School of Economics and Management, \\ University of Minho, Braga, Portugal
}

\begin{abstract}
Purpose - The purpose of this paper is to assess the extent to which Portuguese companies have incorporated equality- and diversity-related issues into their management discourse, and examine the prevalent rhetoric on these matters.

Design/methodology/approach - A comprehensive content analysis of the web sites of the 500 largest companies plus the 20 best companies to work for in Portugal, in 2005, according to the ranking of The Great Place to Work ${ }^{\circledR}$ Institute Portugal.

Findings - The analysis of the web site data shows that equality and diversity rhetoric mirrors, to a large extent, the dominant US discourse and ignores the necessary adaptation to the local context. However, there are significant differences in the adopted rhetoric according to the origin of the ownership control (native vs foreign) and the intended audience (local vs global). Native owned companies with web sites intended to a local audience tend to ignore diversity issues altogether.

Research limitations/implications - The study was limited to a single country's data, and to the discourse rather than actual practices. However, the paper adds to the debate on the globalization of management knowledge stressing the limitations of adopting the "one size fits all" management rhetoric as opposed to developing rhetoric more appropriate and that fits into the local context.

Originality/value - The paper provides an account of the equality and diversity rhetoric adopted by the most prominent organizations operating in Portugal, suggesting that such rhetoric is mainly for external consumption.
\end{abstract}

Keywords Equal opportunities, Rhetoric, Diversity, Globalization, Localization, Portugal

Paper type Research paper

\section{Introduction}

Many social, economic, and political factors have contributed to the growing diversity of Western societies. Although slower and harder to move than information or capital, the increasing mobility of people is a key feature of the current process of globalization (Tomkiewicz et al., 2002; Lindio-McGovern, 2003). Since ancient times, poor social and economic conditions have led to significant migratory flows, but daily access to images of the more affluent societies stimulate millions of people who barely make ends meet to move out and search for their own "eldorado" elsewhere. Career ambitions of young professionals, the adoption of flexibility practices in the work context, and the end of "jobs for life" also force people to move to other places in the same country, or abroad, in growing numbers. Supranational arrangements such as the European Union allow people to move freely between European countries and promote the expatriation of professionals. As a result, people from a variety of nationalities, ethnicities, races, beliefs, sexual identities and orientations, ages and appearances, physical and mental conditions, sets of values, traditions, qualifications, and experiences have been increasingly colouring the workplace in Western countries (e.g. Milliken and Martins, 1996).

Considerable improvements in transportation and the remarkable technological developments in communication systems make the world look smaller allowing

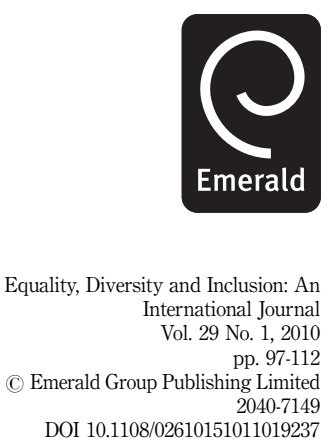


EDI

29,1

98

individuals to online access the whole world and to work in virtual teams and, ultimately, to reassess their sense of closeness and localness. The meaning of proximity, community, and neighbourhood is losing its geographical dimension, and the world is becoming "one world". And yet, the world still looks different when seen from different places.

Driven by global market forces and the neo-liberal orthodoxy, the current globalization process is unravelling new conflicting interactions, tensions, and contradictions between different logics, and widening economic disparities within and between societies (Chow, 2003). Tensions are apparent between global competitive pressures and single country needs and demands, and tensions between global corporate strategies and the specificities of local social and cultural contexts (Rosenzweig, 2006). But tensions are also apparent between the growing workforce diversity, on the one hand, and the homogenization of political and social structures leading to the reduction in the diversity of state policies and practices, on the other (Walby, 2004).

At the management level, the current globalization process has certainly contributed to standardize approaches and practices, but it has failed so far to override the specificities of the local contexts. In multinational corporations (MNCs), managing the human factor involves a continuous interplay between pressures for internal consistency and for local adaptation (Rosenzweig, 2006). The development of a common management philosophy and discourse shared by headquarters and the affiliates is sought, but the translation of global management values and principles into practice is not always consistent with the particularities of the local context (e.g. Hearn et al., 2006; Rosenzweig, 2006). Understanding the local context remains critical to management effectiveness. Issues of equality and diversity are particularly sensitive to local cultures and, therefore, provide an excellent opportunity to assess the extent to which underestimate the local context may have detrimental effects on the corporate managerial effectiveness.

Since the early 1990s, issues of equality and diversity, and the management of sameness and difference in the workplace have become hot topics in the management agenda (Tsui et al., 1992; Liff and Wajcman, 1996). This is particularly evident in the US literature, and to a less extent in the UK. In Continental Europe, however, the topic remains somewhat marginal. On the other hand, in most European countries, equality and diversity research and practice seems to be excessively influenced by the concepts and frameworks derived from studies conducted in the US context. More often than not, the specific social, economic, and political dimensions of the local context fail to attract attention and the uncritical adoption of the originally US equality and diversity discourse appears to prevail. Whether, or not, that is the case in Portugal is the focus of this paper. This study aims to examine the equality and diversity rhetoric of both local and global companies operating in Portugal, by content analysing their web sites.

\section{Discourses and realities of managing diversity}

Human history provides numerous examples of conflicts and tensions between people around issues of difference and otherness. Dealing with uncertainty and deviation from the norm raises a sense of discomfort and apprehension. In contexts dominated by fear and ignorance, the difference may be interpreted as disintegration, oddness and danger, or as something to avoid or even to eradicate (Elmes and Connelley, 1997). In the last decades, workplaces have become more heterogeneous in terms of demographics, values, and lifestyles. Dealing with the "other" is now part of daily life in most 
organizations. Many factors have contributed to this widening diversity, not least the current process of globalization.

As a result of what Chow (2003) referred to as the powerful forces of globalization, there is a growing mobility of people across boundaries, nation states, and cultures, leading to an increasing workforce diversity. In this new context, highly qualified workers are able to move freely and get an easier access than before to knowledge intensive well-paid jobs abroad. But the current globalization process has also fostered the supply of a cheap, docile, and disposable labour force from the economic south to the economic north, a process that has been described as modern slavery and a new form of human trafficking (Lindio-McGovern, 2003). Lacking the required educational and skill attributes, members of the migrant communities often remain second-class citizens in the host countries, adding class inequalities to ethnic inequalities (Chow, 2003). On the other hand, as global corporations become more powerful and influential, more pressure is put on nation states to deregulate work relations and reduce social protection, including the extent and quality of welfare provision (Acker, 2006).

Globalization has also emerged as a gendered phenomenon that is challenging the existing inequality regimes (Acker, 2006) and the gendered division of labour (Chow, 2003). Although generating new employment opportunities for women and increasing female labour force participation and economic independence, the globalization process is also reinforcing the feminization of labour in segregated and low-paid jobs, thus contributing to perpetuate power unequal relationships between men and women (Hearn et al., 2006). This outcome illustrates how gender is interlocked with other stratifying factors and how besides contributing to the growing mobility of people, the current globalization process seems to be promoting and perpetuating inequalities based on class, nationality, race, and gender (Chow, 2003; Walby, 2004). These multiple inequalities are neither independent nor static. Understanding the relationship and intersections between different inequalities, the "hierarchy" of inequalities, and the increasing dynamics and "competition" between inequalities (Verloo, 2006) are essential steps to an effective and consistent equality policy design. Diversity and inequality are, therefore, intertwined and inescapable features of today's societies that influence and shape the way organizations manage their human resources.

As pointed out above, issues of equality and diversity in the workplace were first raised in the US context. The traditional way of dealing with diversity became known as the "melting-pot" metaphor. According to this perspective, minorities should hide their cultural particularities in the workplace and assimilate the traditions, values, and ways of acting and expressing of the dominant group. As a reward, there was an implicit promise of success to those individuals who learned how to fit in. The assumption behind this approach was that differences were simply transitory and equality would be somehow guaranteed by homogeneity.

This melting-pot approach did not prevent discrimination in the workplace and was, therefore, challenged by the social movements of the 1960s towards equal opportunities for men and women and the civil rights of minorities. A legalistic approach was adopted suggesting that individuals should receive equal treatment and enjoy the same rights and duties in the workplace (Liff, 1997). Under the Equal Employment Opportunity framework, an attempt was made to prevent discrimination based on features that were not related to performance and qualifications (CarrRuffino, 1996). In case of proved discriminatory conduct, the employer would be penalized with mandatory remedial hiring policies and back pay awards, besides damaging its public image (Carrington et al., 2000). These preventive measures did not
Equality and diversity rhetoric 
EDI

29,1

100 apply to individuals in general, but rather to those belonging to disadvantage groups presumed more likely to be discriminated against.

The equal opportunities approach was blind to the particular needs and disadvantages faced by women and ethnic minorities as a result of their different patterns of qualifications, work experiences, and domestic responsibilities. Assuming that organizations should mirror the social diversity of the community at large, affirmative action programmes were set up aiming to reverse that discrimination. The difference was now protected and individuals were treated according to their identity group of origin. Corrective measures such as hiring quotas were always involved in great controversy and were gradually abandoned (Carrington et al., 2000).

In the late 1980s, a new approach to diversity emerged regarded as building on equality and moving the agenda forward to include non-visible individual differences (Kirton and Greene, 2005). Diversity was no longer regarded as a threat, but as an asset worth valuing. In order to benefit from a diverse workforce, organizations developed policies and practices that took advantage of the presence, commitment, and performance of individuals from different backgrounds. Management policies were designed addressing the work-life balance and developing organizational cultures that welcome, support, and value diversity (Cox and Blake, 1991; Lorbiecki, 2001). The expectation was that in this way, organizations would benefit in terms of innovation, networking, and access to other markets.

This strategic and business driven approach represents an important shift from "we're all alike (or should be)" to "we're each unique and that's the source of our greatness" (Carr-Ruffino, 1996, p. 20). The "equality based on sameness" paradigm was replaced by the "equality based on difference" paradigm (Liff and Wajcman, 1996). Under this new perspective, equality and rewards are better achieved through the recognition of each individual's own identity rather than his/her group identity.

Despite the European diversity, this debate has remained somewhat surprisingly absent from the European agenda. The initial policy measures were taken along similar lines to the US Equal Employment Opportunity approach and focused on equality between women and men and on the recruitment of individuals with disability (Verloo, 2006). Only afterwards and possibly as a reflection of the growing presence of ethnic and racial minorities did other dimensions of diversity such as race and ethnicity manage to attract attention from European governments and policy makers (as confirmed by the Council Directives 2000/43/EC and 2000/78/EC).

Several developments in the last two decades have contributed to an increasing demographic diversity in Europe. Besides the already mentioned globalization process, the establishment of the single market allowing the free movement of people between E.U. member states, the enlargement and admission of former Eastern Bloc countries, and an increasing influx of migrants from other continents have shaken the traditional demographic homogeneity of European workplaces. Concerns with the social and economic integration of migrants have jumped to the top of the political agenda in many European countries. Even in countries not traditionally receptors of a foreign workforce, managers had to learn how to deal with the "different" workers. Dealing with diversity and the "otherness" suddenly became, in one way or another, a matter of concern for most managers across Europe (Simons, 2002). And issues of sameness and difference have gradually found its way into European journals (e.g. Liff and Wajcman, 1996).

However, diversity research is still at an early stage of development in most European countries. Little is yet known about the way organizations go about diversity 
issues. Gender diversity issues are perhaps the one exception, having attracted considerable attention from researchers and policy makers. Mainstreaming was initially presented as entailing "a paradigm shift in the thinking towards the development of policy and practice" (Rees, 1998, p. 194), but only gender mainstreaming was officially adopted as a European policy attempting to incorporate a gender equality perspective in all organizational processes and practices (e.g. Benschop and Verloo, 2006; Verloo, 2006; Walby, 2004). Other diversity issues were somewhat left at the margins, despite the current signs that the European policies are "moving from a predominantly focus on gender inequality, towards policies that address multiple inequalities" (Verloo, 2006, p. 214). The academic agenda has apparently mirrored the policy actors' agenda. The research effort to examine diversity issues in the European context has so far been insufficient and unable to address the concerns of many European stakeholders.

The limited number and scope of the studies about diversity issues in the European context has "forced" practitioners to rely on the rhetoric available in the literature, basically developed for the US context. However, the adoption of an "alien" rhetoric deprived of any critical evaluation and adjustment to the local context rarely leads to effective solutions (Abrahamson, 1996; Ercek, 2006). Examining what goes on with regard to equality and diversity in the European context is, therefore, of critical importance to advancing the understanding of these issues.

\section{Studying the rhetoric of equality and diversity}

To what extent are European organizations aware of equality and diversity issues? What kind of diversity issues are they concerned with? And when they care about equality and diversity, what is the rhetoric adopted? Are they simply following the US rhetoric on this matter and adopting similar practices to the ones adopted by US organizations? To what extent are they tailoring that rhetoric to the local audience? These are the type of background questions this study intends to address.

The globalization process has contributed to the worldwide adoption of management values and practices, and the emergence of a global management discourse (Hearn et al., 2006), but this global discourse often fails to respond to the local demands. The human rights and equality discourse is a good example of rhetoric fitting nicely into the corporate image that is often watered down when translated into local action. More often than not, the inclusion of corporate social responsibility initiatives and the promotion of human rights in the rhetoric adopted by MNCs is contrasted with their practice of exporting low-paid and low-skilled jobs to less developed countries, and promoting differential work and wage conditions for women and men (Hearn et al., 2006; Lindio-McGovern, 2003). Time and again, a mismatch between the exposed (global) rhetoric and the actual (local) practices comes to surface.

Evidence has been provided showing that management rhetoric tends to go ahead of reality, namely in human resource management (e.g. Bowles and Coates, 1993; Cabral-Cardoso, 2006; Hamilton, 2001; Keenoy, 1990; Storey and Sisson, 1990). This contributes to the popular view of rhetoric as "a form of language use with little substance and [that] is more concerned to mislead and impress its audience through the use of clever linguistic and presentational tricks than to provide realistic and useful information about the topic addressed" (Watson, 1995, p. 7). In daily life, expressions such as "things are easier said than done" and "actions speak louder than words" are commonly used to highlight not only the disparity between talk and action but also the
Equality and diversity rhetoric 
EDI

29,1

102

valuing of action over discourse (Grant et al., 1998, p. 5), thus representing talk and action as "separated [identities] in time as well as space" (Marshak, 1998, p. 18).

This perspective ignores other more positive views of rhetoric. Grant et al. (1998) acknowledge the relevance of the discursive skills in managerial roles such as organizing, planning, leading, motivating, coordinating, controlling, and networking. And Dunford and Palmer (1998) admit that discourse constitutes a form of action, though not very "active", being fundamental to the elucidation of behavioural and attitudinal expectations. They argue that discourse can generate "emotional energy" that is essential in processes of organizational change (p. 216). The discursive skills of leaders and managers can, thus, play a decisive role in the adoption, development, and consolidation of new managerial models and philosophies. Managing diversity in the European context fits into that description: it may require some "emotional energy" to take off, and rhetoric can be instrumental in that process.

These are two apparently antagonistic perspectives: "rhetoric and action" and "rhetoric vs action". Which one prevails in the equality and diversity? Is it a case of "mere rhetoric" or of "effective rhetoric"? In other words, is the equality and diversity discourse used mainly for window dressing and improvement of the organizational image in public opinion? Or, is it used with the actual aim of mobilizing its audience to a particular course of action and as an engine for organizational change?

\subsection{The study}

This study addresses the equality and diversity rhetoric adopted by Portuguese companies. What make Portugal an interesting context for studying diversity issues are the unique features of its social and cultural background. A brief look at the Portuguese context is, therefore, necessary.

\subsection{The Portuguese context}

Portugal was until the 1960s an agrarian society with a low-qualification low-wage workforce mainly employed in public administration and in traditional industrial sectors highly dependent on the protected markets of the colonies. Portuguese society was then one of the most demographically homogenous societies in Europe with the oldest stable border (virtually unchanged for many centuries), and only "residual" linguistic, religious, and ethnic minorities. This state-of-affairs was dramatically shaken by two major political events that transformed the fabric of Portuguese society: The democratic revolution of 1974 with the subsequent loss of the colonies, and the integration in the European Union, in 1986. By the late 1990s, all spheres of society had witnessed significant changes, namely in terms of inequality and diversity (CabralCardoso, 2006). In the last two decades, asymmetric economic development has led to growing social differences widening the gap between those with high and low income, and between the industrialized urban areas along the coast and the rural heartland. By the turn of the century, Portugal already had the largest wage inequality in Western Europe (Grimshaw and Rubery, 2001) and the adoption of neo-liberal policies has since then reinforced that trend. In the meantime, an economic surge has attracted an important migrant population from Eastern Europe, Brazil, and the old African colonies. This growing inequality and diversity is one of the most significant changes in Portuguese society with a clear impact on management and organizations (CabralCardoso, 2006). Gender is possibly the one exception to this trend towards widening inequality, mainly due to the increasing access of women to education and raising status in society. 
And yet, the traditional traits of Portuguese organizational culture remain largely untouched (Cunha, 2005; Jesuíno, 2002). Equality is more likely to be achieved as a result of patronizing workplace relations than out of respect for the minority rights. All in all, the economic, political, social, and cultural traits of Portuguese society are quite dissimilar to the ones identified in the US context (Hofstede, 1991), thus making Portugal a considerable challenge for the originally US equality and diversity rhetoric to translate into practice (Cabral-Cardoso, 2006; Cunha, 2005) and an interesting location to conduct this study.

\section{Method}

The diversity rhetoric is examined through a comprehensive content analysis of the web sites of the 500 largest companies plus the 20 best companies to work for in Portugal, in 2005, according to the ranking of The Great Place to Work ${ }^{\circledR}$ Institute Portugal (2005). "Fairness" was included among the criteria used to select the best places to work.

Web pages have become privileged communication tools to reach a growing number of people, particularly among the most prominent companies. On their web site, companies can include a vast amount of information and portray a certain image aiming to impress and persuade specific audiences (Hill and White, 2000).

The web sites were content analysed considering the following analytical categories:

- organizational values related to diversity;

- minorities in the organization, with two sub-categories: diversity dimensions and benefits for the organization;

- managing diversity initiatives, policies, and practices;

- diversity awards and recognition; and

- specific links to issues of diversity.

Table I includes the key terms associated with each of the analytical categories.

\section{Findings}

5.1 Web sites with references to equality and diversity issues

In the sampled companies, 352 were found to have a web site. Through content analysis of these web sites, references were found to philosophies, objectives, and initiatives of managing diversity in approximately 15 per cent (54 out of 352 companies) of all the companies with an available web site at the time the research was conducted. This group of 54 companies is made of 50 belonging to the top 500 and ten belonging to the 20 "Best Companies to Work for in Portugal". Among those holding a web site with references to equality and diversity issues, only six companies were simultaneously part of the "largest" and the "best" places to work samples.

This evidence is quite revealing. Only a small fraction (15 per cent) of the sampled companies considers that equality and diversity issues are relevant enough to deserve being referred to in their web sites. Even among the so-called "best companies to work for", only half of them refer to matters of equality and diversity in their web sites. In other words, equality and diversity issues seem to be kept out of the management agenda in most cases or, at least, not be regarded as worth mentioning in their web sites. That is the case even in companies that were part of the "best place to work for" group.
Equality and diversity rhetoric

103 
EDI
29,1

104
Analytical categories Key terms

Organizational values related to diversity

Change
Creativity

Communication

Diversity

Equal opportunities

Ethics

Excellence

Free expression

Inclusion

Innovation

Meritocracy

Mutual respect

Openness

Teamwork

Minorities in the organization Diversity dimensions

Benefits for the organization

Managing diversity initiatives Policies and practices

Diversity awards and recognition

Specific link to issues of diversity (examples)
Age

Civil status

Class

Education

Gender

Language

Nationality of origin

Physical appearance

Physical condition

Political ideology

Pregnancy

Race/ethnicity

Religion

Sexual orientation

Union membership

Every person is unique

Business case

Improvements in decision-making processes Increased flexibility

Innovation and learning

Market competitiveness

Development of an inclusive culture

Diversity councils

Diversity training

Minorities recruitment

Minorities integration

Minorities career development

Work-life balance initiatives

Awards

Public recognition

Citations in the media

Diversity and work life

Diversity statement

Embracing diversity

Careers: diversity policy
Table I.

Analytical categories 
Bearing in mind that fairness was included among the performance criteria taken into account in that ranking, this finding is rather informative.

The sampled companies were categorized according to the origin of the ownership control - native or foreigner - and the web site's targeted audience. Table II shows the combination of these two criteria. The language used in the web site was adopted as the criteria to identify the intended audience:

(1) The adoption of the native language was interpreted as targeting the local market.

(2) The adoption of the English language was interpreted as targeting the global market.

Combining the two criteria, four types of companies were identified:

(1) Type A companies, with native ownership control and web sites that are apparently directed to the local audience (using Portuguese language): 11 in total.

(2) Type B companies, with native ownership control and web sites that are apparently directed to an international audience (using English language): two in total.

(3) Type C companies, with foreign ownership control and web sites that are apparently directed to the local audience (using Portuguese language): 14 in total.

(4) Type D companies, with foreign ownership control and web sites that are apparently directed to an international audience (using English language): 27 in total.

This crude distribution is worth some reflection. About 30 per cent of the companies with foreign ownership control with available web site at the time the research was conducted exhibited references to equality and diversity (41 out of 137), whereas only 6 per cent of the companies of Portuguese ownership control with available web site at the time the research was conducted did the same (13 out of 215). It appears that the vast majority of the Portuguese owned companies find that equality and diversity issues are not valued by their stakeholders and, therefore, see no justification to mention those matters in their web sites. Although this is a limited sample, these findings point towards equality and diversity being, to some extent, an imported rhetoric that does not appeal to the local audience.

Types $\mathrm{C}$ and $\mathrm{D}$ companies, that is to say, foreign owned companies that mention equality and diversity issues in their web sites, were mainly of US or UK origin, as indicated in Table III. This is hardly a surprise bearing in mind the US roots of the concerns with equality and diversity issues in work organizations. On the other hand, British companies were found to be among Europeans, the most enthusiastic adopters of US management models of managing people (Guest, 1990).

A comprehensive content analysis of the web sites of the 54 companies was conducted considering the categories described above. Then, for each group of

\begin{tabular}{|c|c|c|}
\hline \multirow[b]{2}{*}{ Origin of the companies' ownership control } & \multicolumn{2}{|c|}{ Web site's targeted audience } \\
\hline & Local & Global \\
\hline $\begin{array}{l}\text { Portuguese } \\
\text { Foreign }\end{array}$ & $\begin{array}{l}\text { Type } A=11 \\
\text { Type } C=14\end{array}$ & $\begin{array}{l}\text { Type } B=2 \\
\text { Type } D=27\end{array}$ \\
\hline
\end{tabular}

\section{Equality and diversity rhetoric}

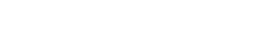


29,1

106
EDI

companies (types A, B, C, and D), data were examined by analytical category. The findings are presented using the same process.

\subsection{Native companies with web sites directed to a local audience}

Most type A companies, that is to say, native owned companies with web sites apparently directed to a local audience, include references to values that could be interpreted as particularly favourable to heterogeneous workgroups and to the development of their full potential (e.g. Goodman et al., 2001). Lactogal, a dairy group, provides a good example of this stance:

We encourage innovation and teamwork and value our workers. [...] We share information, recognition and the goals we want to achieve, and we are sympathetic to each other in the case of success as well as failure. We assure equal opportunities and recognition.

In general, the discourse of type A organizations condemns discrimination and highlights the importance of granting the same rights and duties to everyone in the workplace, seen as equal individuals in the work setting. When references are made to specific policies or practices, they tend to be limited to recruitment processes, and to issues already covered by legislation. In other words, the legalistic discourse appears to prevail and discrimination issues in organizational processes other than recruitment are ignored. No additional references are made to practical initiatives in managing diversity, which may cast some doubts on the daily translation of the espoused values.

Two cases were found taking a different stand: Petrogal (oil refinery and distribution) and Companhia Portuguesa de Hipermercados (retailing). Both announce recruitment and career development practices directed to individuals with disability, even though they do not explicitly refer to equal opportunities or diversity management in their web sites. But no reference is made to the benefits derived from the presence of this minority group.

\subsection{Native companies with web sites directed to an international audience}

Type B companies, that is, native owned companies with web sites directed to a global audience, point out equal opportunities and diversity among their critical values. However, only Accenture (consulting) considers that a culturally heterogeneous workforce has contributed to problem solving effectiveness, a contribution the literature tends to associate with diversity (e.g. Brickson, 2000). As for practical initiatives in managing diversity, the same company highlights its commitment to the development of a favourable environment for diversity, which is another measure strongly praised by the literature in this area (Cox and Blake, 1991):

Accenture strives to attract and retain the best people and provide an environment where they can all develop professionally and build a rewarding career. As a result, we have an environment rich in diversity that acknowledges each individual's uniqueness, values his or her skills and contributions, and promotes respect [and] personal achievement.

Total (type C + type D)

Percentage

\section{Table III.}

Companies of foreign ownership control
USA and UK

Other nationalities

Total
23 (out of 39 )

18 (out of 98 )

41 (out of 137)
59

18

30 


\subsection{Foreign companies with web sites directed to a local audience}

Type $\mathrm{C}$ organizations, foreign owned companies with web sites that are aimed at the local audience appear to adopt the global equality and diversity rhetoric. US and UK owned companies often tend to associate diversity with "inclusion". The literature on diversity defines an inclusive organization as a culture that embraces all human differences (Cox and Blake, 1991). These companies assume their commitment to equal opportunities including diversity dimensions that were not traditionally contemplated in Portuguese legislation, such as age, sexual identity, and sexual orientation. Very much in line with the literature on diversity (Dass and Parker, 1999), type C companies also seem confident of the benefits brought in by minorities in their workforce, and regard them as a source of competitive advantage. Xerox's web site provides a good example of this viewpoint:

Diversity is the key to success. Experience shows us that the more diverse companies [...] will be the most successful. In some way, diversity promotes creativity.

With regard to managing and promoting diversity initiatives, type $\mathrm{C}$ companies highlight the recruitment of individuals from disadvantaged groups (mostly women and people with disability), work/life policies, and practices such as flexible work scheduling and diversity training. References to diversity awards and recognition were also found in the web sites of these companies. For instance, IBM Portuguesa (IT sector) has won the "Equality is Quality" award. In its own words, such an award "aims to reward the companies and institutions that promote equality between women and men, in terms of access to work and career development, and in what refers to life/work balance". It is also worth noting that several type $\mathrm{C}$ companies have specific diversity links in their web sites. The two best examples were found in the web sites "Promoting diversity" of Tabaqueira (tobacco manufacturer) and "Diversity and inclusion" of HP Portugal (IT equipment).

\subsection{Foreign companies with web sites directed to an international audience}

As expected, foreign owned companies with web sites directed to an international audience (type D) also follow the global equality and diversity rhetoric. These organizations assume organizational values that favour the development and the full potential of a diverse workforce. Microsoft (IT sector) provides a good example:

As a company, and as individuals, we value integrity, honesty, openness, personal excellence, constructive self-criticism, continual self-improvement, and mutual respect.

The belief that a diverse workforce can contribute to organizational performance is apparent in most type D companies. More than an ethical or legal obligation, the presence of minorities is viewed as a strategic asset. The Bayer's President and CEO (pharmaceutical) states:

I strongly believe that not only is fostering diversity the right thing to do, but that there is actually a solid business case for having a diverse workforce.

The recognition and valuing of each individual's characteristics and contributions is a typical feature of the rhetoric of "equality based on difference" (Thomas and Ely, 1996). The following statement, from Johnson \& Johnson (chemical) is a good illustration of this perspective:

At Johnson \& Johnson, diversity is defined as a variety of similar and different characteristics among people [...]. This definition recognizes that individually we all have differences of some sort from which we can share and learn. Some of those differences are obvious while some may not be so obvious. 
EDI

29,1

108
Commitment to the development of an inclusive organizational culture stands out among the vast list of practical initiatives on diversity management, meaning a workplace free from practices, attitudes, and behaviours that threat human dignity. Tyco Electronics provides a good example of this commitment:

One of Tyco's key goals is to maintain a work environment free from discrimination, harassment, or personal behaviour that is not conducive to a productive work climate. We are steadfast in our commitment to provide a workplace environment free from intimidation, threats, and violent acts.

Other initiatives include diversity councils, work/life policies and practices, and diversity training. References to affirmative action programmes were found in the web sites of some companies, although restricted to the branches located in the USA. The web sites of several type D companies mention diversity awards and recognition but here, again, the vast majority is related to the activity of US branches. This is not surprising, since these awards are much more common in the USA than in Europe in general. It is worth noting that most type D companies have been integrated into the list of the "best places to work for" in several countries. For example, Microsoft was considered the best place to work in Portugal in 2005, according to The Great Place to Work Institute Portugal (2005).

It is significant that most web sites of type D companies have specific links to diversity policies and practices, such as "Diversity and work life" (Bristol Myers Squibb), "Diversity statement" (Goodyear Dunlop Tyres), "Diversity and inclusion" (SAP), and "Embracing diversity" (Unilever Bestfoods). And here again, this feature is predominant in the web sites of US owned companies, thus confirming that the diversity discourse is particularly valued by organizations originated in that country.

\section{Discussion and conclusions}

Although limited to a single country data, and to the discourse rather than actual practices, the paper adds to the debate on the globalization of management knowledge stressing the limitations of adopting the global management rhetoric as opposed to developing rhetoric more appropriate and that fits into the local context.

The analysis of the companies' web sites shows that the equality and diversity rhetoric is, to a large extent, an imported one. Most Portuguese owned companies appear not to have a policy on equality and diversity or if they do, it is not regarded as relevant enough to be mentioned on the web site. This is particularly the case when the web sites target the local audience (type A companies), which suggests that local external stakeholders do not value diversity initiatives, and the workers and the unions do not demand them. "Diversity and equality" professionals (Wahl and Höök, 2007) are also absent from these organizations.

The fact that disclosing diversity initiatives, policies, and practices is more frequent in web sites aimed at the international audience further reinforces the conviction that the local constituencies do not take diversity as a priority in their agenda. In contrast, foreign owned companies (types C and D) seem eager to publicize their equality and diversity initiatives. Where equality and diversity issues are referred to, it is the "one size fits all" approach that tends to prevail. These findings appear to confirm the key role played by MNCs in the transfer of management knowledge and rhetoric to the local organizations (Cunha, 2005).

Additionally, some subtle differences were detected according to the origin of the ownership control (Portuguese vs foreign) and the targeted audience of the web sites 
(local vs global). Type A companies adopt a legalistic discourse, while types C and D companies (foreign owned) prefer a more strategic one. This is particularly noticed in US and UK owned companies in which the business case for diversity prevails, very much in line with the current dominant paradigm in the literature. The view of the worker as a unique individual with particular needs is mainly detected among foreign owned companies with web sites directed to a global audience (type D companies). Most type $C$ and type D companies namely those of UK and US origin, indicate in their web sites several practical initiatives in managing diversity.

In sum, an examination of the web sites of the most prominent companies operating in Portugal has shown that equality and diversity issues are somewhat marginal in the organizational discourse particularly when the discourse is directed to a local audience, thus reflecting the current state of the debate on those issues in Portuguese society. It also shows that the convergence of management values and practices and the development of a global management discourse as a result of the current globalization process (Hearn et al., 2006) are still at an early stage. However, the findings also show that where the equality and diversity rhetoric has made its way to the companies' web sites, it is the adoption of the dominant US and UK discourses on these matters that prevail with little adaptation to the local context. In fact, very few signs of adaptation to the local cultural traits were detected. Although concerns about internal consistency in the MNCs' policies (Rosenzweig, 2006) might partly explain that behaviour, it is also likely to reflect the view of US management knowledge as universal knowledge. It is somewhat ironic that a sophisticated discourse on diversity falls short of sensitivity to ... contextual diversity.

\section{Suggestions for further research}

This study looked at discourses rather than actual practices. Whether, or not, the different discourses detected in the companies' web sites are translated into different management practices requires further examination and a different research methodology. In-depth case studies of the A-to-D type of companies may add to the debate about the adoption vs adaptation of management knowledge (Cunha, 2005), and shed some more light on the impact of US rhetoric in equality and diversity in the European context. Bearing in mind the discrepancies between rhetoric and reality that have been found in other management areas (Cabral-Cardoso, 2006), examining the actual practices of the various companies is likely to be very insightful. A comparative study of the web sites of the most prominent companies located in other European countries would give a better idea of the extent of that discrepancy.

Further research on the diversity practices adopted by types $\mathrm{C}$ and $\mathrm{D}$ companies could also contribute to assessing the extent to which global organizations with an equality discourse are actually promoting equal opportunities in the countries where they operate rather than utilizing that discourse mainly to impress the audience in their country of origin (Chow, 2003). Other studies reported in the literature seem to give credit to this point. Some of MNCs' policies and practices were found to promote and perpetuate inequalities based on race, gender, class and nationality, and for debilitating the financial wealth of SMEs at early stages of internationalization (e.g. Acker, 2006; Walby, 2004). Further research on the diversity practices adopted by affiliates of MNCs would shed some more light on the question as to whether the logic of "keeping internal consistency" prevails over the logic of "adjusting to the local context", and who and what is pushing in what direction. The global integration/local responsiveness
Equality and diversity rhetoric

109 
EDI

29,1

110

framework (Rosenzweig, 2006) may also provide a useful perspective for exploring those issues.

The role played by business education in this state-of-affairs also deserves further attention. Studies conducted elsewhere have looked at business schools and how they can make a significant contribution towards the understanding of diversity as a business issue (Levin and Mattis, 2006). The findings of the current study seem to suggest that business schools in this country have not played any significant role in raising awareness of diversity issues. Exploring the views of the academic business community about these matters could be very revealing. The role played by manuals and textbooks in the dissemination and globalization of the dominant management rhetoric on diversity (Litvin, 1997) has also been overlooked and requires further examination.

A longitudinal study of the web sites of the most prominent Portuguese companies (types A and B) would give valuable information about how diversity rhetoric is evolving, and would allow the assessment of the extent to which the global discourse is being adopted. It would also allow the identification of the efforts (if any) that are being made to adapt that discourse to the local context. Mimic the US management fads and fashions have always been very tempting (Abrahamson, 1996; Watson, 1995) but may well prove unwise for managers elsewhere.

\section{References}

Abrahamson, E. (1996), "Management fashions", Academy of Management Review, Vol. 21 No. 1, pp. 254-65.

Acker, J. (2006), "Inequality regimes: gender, class, and race in organizations”, Gender \& Society, Vol. 20 No. 4, pp. 441-64.

Benschop, Y. and Verloo, M. (2006), "Sisyphus' sisters: can gender mainstreaming escape the genderedness of organizations?”, Journal of Gender Studies, Vol. 15 No. 1, pp. 19-33.

Bowles, M.L. and Coates, G. (1993), "Image and substance: the management of performance as rhetoric or reality?”, Personnel Review, Vol. 22 No. 2, pp. 3-21.

Brickson, S. (2000), "The impact of identity orientation on individual and organizational outcomes in demographically diverse settings", Academy of Management Review, Vol. 25 No. 1, pp. 82-101.

Cabral-Cardoso, C. (2006), "Portuguese management between global rhetoric and local reality: the case of human resource management”, Management Research, Vol. 4 No. 3, pp. 193-204.

Carr-Ruffino, N. (1996), Managing Diversity: People Skills for a Multicultural Workplace, International Thomson Executive Press, Cincinnati, $\mathrm{OH}$.

Carrington, W.J., McCue, K. and Pierce, B. (2000), "Using establishment size to measure the impact of title VII and affirmative action”, Journal of Human Resources, Vol. 35 No. 3, pp. 503-23.

Chow, E.N. (2003), "Gender matters: studying globalization and social change in the 21st century", International Sociology, Vol. 18 No. 3, pp. 443-60.

Cox, T.H. and Blake, S. (1991), "Managing cultural diversity: implications for organizational competitiveness", Academy of Management Executive, Vol. 5 No. 3, pp. 45-56.

Cunha, M.P. (2005), "Adopting or adapting? The tension between local and international mindsets in Portuguese management”, Journal of World Business, Vol. 40 No. 2, pp. 188-202.

Dass, P. and Parker, B. (1999), "Strategies for managing human resource diversity: from resistance to learning”, Academy of Management Executive, Vol. 13 No. 2, pp. 68-80. 
Dunford, R. and Palmer, I. (1998), "Discourse, organization and paradox", in Grant, D., Keenoy, T. and. Oswick, C. (Eds), Discourse and Organization, Sage, London, pp. 214-21.

Elmes, M. and Connelley, D.L. (1997), "Dreams of diversity and the realities of intergroup relations in organizations", in Prasad, P., Mills, A.J., Elmes, M. and Prasad, A. (Eds), Managing the Organizational Melting Pot: Dilemmas of Workplace Diversity, Sage, Thousand Oaks, CA, pp. 148-67.

Ercek, M. (2006), "HRMization in Turkey: expanding the rhetoric-reality debate in space and time", International Journal of Human Resource Management, Vol. 17 No. 4, pp. 648-72.

Goodman, E.A., Zammuto, R.F. and Gifford, B.D. (2001), "The competing values framework: understanding the impact of organizational culture on the quality of work life", Organizational Development Journal, Vol. 19 No. 3, pp. 58-68.

Grant, D., Keenoy, T. and Oswick, C. (1998), "Introduction: organizational discourse: of diversity, dichotomy and multi-disciplinarity", in Grant, D., Keenoy, T. and Oswick, C. (Eds), Discourse and Organization, Sage, London, pp. 1-13.

Great Place to Work ${ }^{\circledR}$ Institute Portugal (2005), Best Workplaces in Portugal 2005, available at: www.greatplacetowork.pt/best/list-pt-2005.htm (accessed 10 January 2006).

Grimshaw, D. and Rubery, J. (2001), The Gender Pay Gap: A Research Review. Equal Opportunities Commission, Manchester.

Guest, D. (1990), "Human resource management and the American dream", Journal of Management Studies, Vol. 27 No. 4, pp. 377-97.

Hamilton, P.M. (2001), "Rhetoric and employment relations", British Journal of Industrial Relations, Vol. 39 No. 3, pp. 433-49.

Hearn, J., Metcalfe, B.D. and Piekkari, R. (2006), "Gender and international human resource management”, in Stahl, G.K. and Björkman, I. (Eds), Handbook of Research in International Human Resource Management, Edward Elgar Publishing, Cheltenham, pp. 502-22.

Hill, N.L. and White, C. (2000), "Public relations practitioners' perception of the World Wide Web as a communication tool”, Public Relations Review, Vol. 26 No. 1, pp. 31-51.

Hofstede, G. (1991), Cultures and Organizations: Software of the Mind, McGraw-Hill, London.

Jesuíno, J.C. (2002), “Latin Europe cluster: From south to north”, Journal of World Business, Vol. 37 No. 1 , pp. 81-9.

Keenoy, T. (1990), "Human resource management: rhetoric, reality and contradiction", International Journal of Human Resource Management, Vol. 1 No. 3, pp. 363-84.

Kirton, G. and Greene, A.M. (2005), The Dynamics of Managing Diversity: A Critical Text, 2nd ed., Butterworth-Heinemann, Oxford.

Levin, L.A. and Mattis, M. (2006), "Corporate and academic responses to gender diversity”, Equal Opportunities International, Vol. 25 No. 1, pp. 60-70.

Liff, S. (1997), "Two routes to managing diversity: individual differences or social group characteristics", Employee Relations, Vol. 19 No. 1, pp. 11-26.

Liff, S. and Wajcman, J. (1996), "Sameness' and 'difference' revisited: which way forward for equal opportunity initiatives?”, Journal of Management Studies, Vol. 33 No. 1, pp. 79-94.

Lindio-McGovern, L. (2003), "Labor export in the context of globalization: the experience of Filipino domestic workers in Rome", International Sociology, Vol. 18 No. 3, pp. 513-34.

Litvin, D.R. (1997), "The discourse of diversity: from biology to management", Organization, Vol. 4 No. 2, pp. 187-209.

Lorbiecki, A. (2001), "Changing views on diversity management: the rise of the learning perspective and the need to recognize social and political contradictions", Management Learning, Vol. 32 No. 3, pp. 345-61.

Equality and diversity rhetoric 
EDI

29,1

112

Marshak, R.J. (1998), "A Discourse on discourse: redeeming the meaning of talk", in Grant, D., Keenoy, T. and Oswick, C. (Eds), Discourse and Organization, Sage, London, pp. 15-30.

Milliken, F.J. and Martins, L.L. (1996), "Searching for common threads: understanding the multiple effects of diversity in organizational groups", Academy of Management Review, Vol. 21 No. 2, pp. 402-33.

Rees, T. (1998), Mainstreaming Equality in the European Union, Routledge, London.

Rosenzweig, P.M. (2006), "The dual logics behind international human resource management: Pressures for global integration and local responsiveness", in Stahl, G.K. and Björkman, I. (Eds), Handbook of Research in International Human Resource Management, Edward Elgar Publishing, Cheltenham, pp. 36-48.

Simons, G.F. (2002), EuroDiversity: A Business Guide to Managing Difference, ButterworthHeinemann, Boston, MA.

Storey, J. and Sisson, K. (1990), "Limits to transformation: human resource management in the British context”, Industrial Relations Journal, Vol. 21 No. 1, pp. 60-5.

Thomas, D.A. and Ely, R.J. (1996), "Making differences matter: a new paradigm for managing diversity”, Harvard Business Review, Vol. 74 No. 5, pp. 79-90.

Tomkiewicz, J., Bass, K., Adeyemi-Bello, T. and Voicys, C. (2002), "Demographics and diversity: graduates of an historically black university confront a growing Hispanic presence", Equal Opportunities International, Vol. 21 No. 3, pp. 12-20.

Tsui, A.S., Egan, T.D. and O'Reilly, C.A. III. (1992), "Being different: relational demography and organizational attachment”, Administrative Science Quarterly, Vol. 37 No. 4, pp. 549-79.

Verloo, M. (2006), "Multiple inequalities, intersectionality and the European Union", European Journal of Women's Studies, Vol. 13 No. 3, pp. 211-28.

Wahl, A. and Höök, P. (2007), "Changes in working with gender equality in management in Sweden”, Equal Opportunities International, Vol. 26 No. 5, pp. 435-48.

Walby, S. (2004), "The European Union and gender equality: emergent varieties of gender regime", Social Politics, Vol. 11 No. 1, pp. 4-29.

Watson, T.J. (1995), "In search of HRM: beyond the rhetoric and reality distinction or the case of the dog that didn't bark”, Personnel Review, Vol. 24 No. 4, pp. 6-16.

\section{Corresponding author}

Carlos Cabral-Cardoso can be contacted at: carlos.cabralcardoso@gmail.com

To purchase reprints of this article please e-mail: reprints@emeraldinsight.com Or visit our web site for further details: www.emeraldinsight.com/reprints 